\title{
Pumping Power \& Flow rate comparison of Double Pipe Corrugated Heat Exchanger (DPCHE) against Smooth Double Pipe Heat Exchanger (SPHE)
}

\author{
Amit Kumar Tiwari ${ }^{1}$, Mr. Chandra Shekhar Koli ${ }^{2}$ \\ Research Scholar ${ }^{1}$ \\ Assistant Professor/Head ${ }^{2}$ \\ Department of Mechanical Engineering, ShriRam College of Engineering \& Management, Banmore
}

\begin{abstract}
Heat Exchangers are indispensable in the development of various industrial and daily use systems. However, the effectiveness of the heat exchangers depends on the geometry, working fluids, type and arrangement of the flow through heat exchangers. A lot of experimentalists are working around the globe to find out the methods on how to enhance the productivity of different fluids with varied properties.
\end{abstract}

Keywords: Heat Exchangers, CFD

\section{Introduction}

In this article analysis of both double pipe corrugated heat exchanger and double pipe smooth heat exchanger has been done by using similar input parameters, geometric considerations and boundary conditions. The steps in both the analysis are similar and are explained below

\section{a) Modeling of double pipe heat exchanger with corrugation}

The area of study in the pipe both in the inner section and the outer section is being generated using a software named ANSYS FLUENT 15.0 design module. The flow of hot water is represented by the inner corrugated fluid domain, which enters from the left and exits from the right. The flow of cold water is shown by the outer section of the pipe, which enters from the right side and exits from the left side. The details of the inner and outer fluid pipe sections with a corrugation pitch of $10 \mathrm{~mm}$ and a corrugation depth of $1 \mathrm{~mm}$ are shown in Fig. 1 


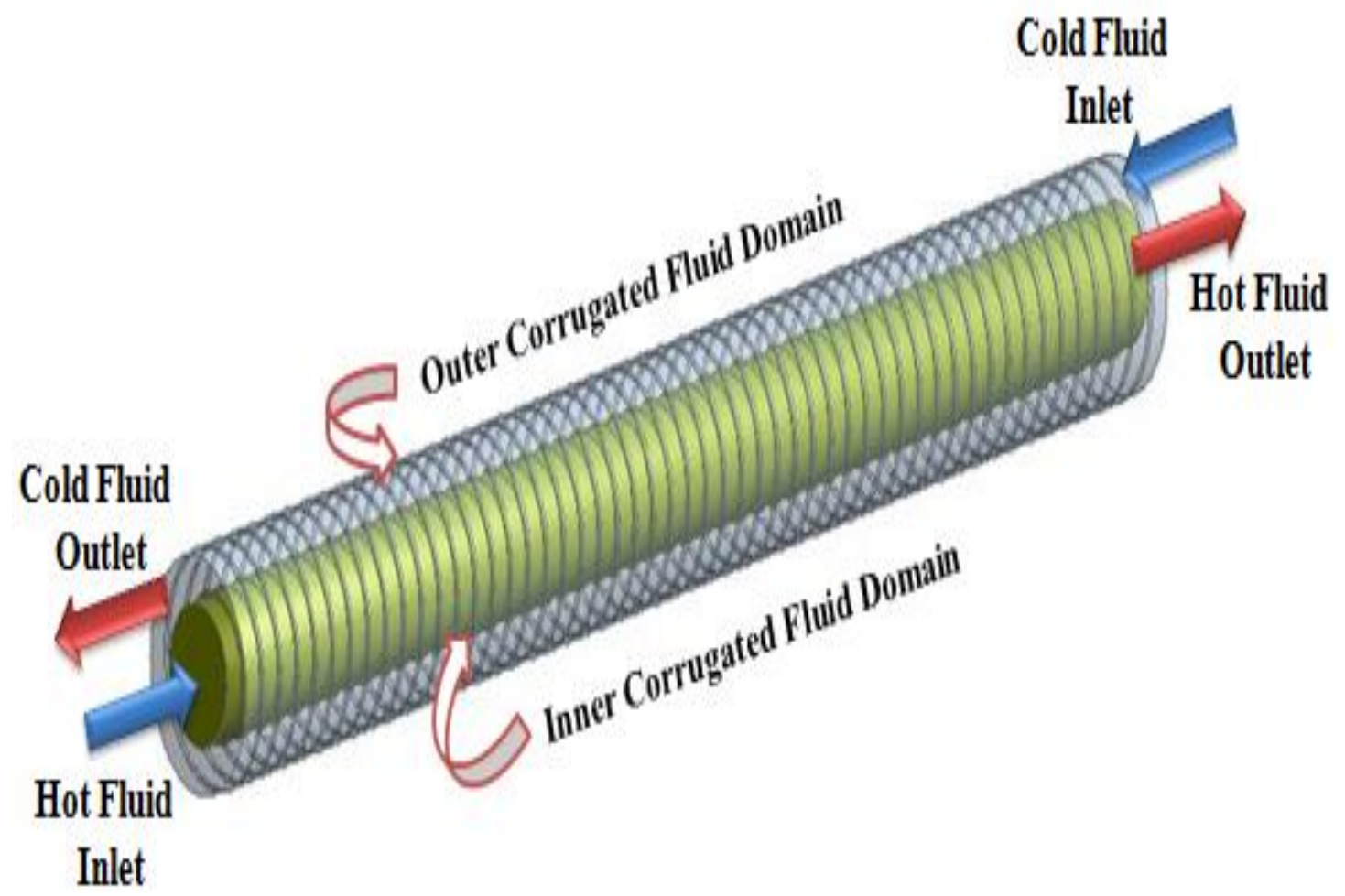

Fig.1Corrugated Fluid domains of hot and cold water

The specifications of these fluid domains for corrugated and smooth pipes are enlisted in Table 1.1 and Table 1.2

TABLE 1.1 GEOMETRICAL SPECIFICATIONS OF FLUID DOMAINS OF DPCHE

\begin{tabular}{|c|c|c|c|c|}
\hline $\begin{array}{c}\text { Length of } \\
\text { DPHE } \\
(\mathbf{m m})\end{array}$ & $\begin{array}{c}\text { Inner pipe } \\
\text { Diameter } \\
(\mathbf{m m})\end{array}$ & $\begin{array}{c}\text { Outer pipe } \\
\text { Diameter } \\
(\mathbf{m m})\end{array}$ & $\begin{array}{c}\text { Corrugation } \\
\text { Pitch } \\
(\mathbf{m m})\end{array}$ & $\begin{array}{c}\text { Corrugation } \\
\text { Depth } \\
(\mathbf{m m})\end{array}$ \\
\hline 518 & 32 & 52 & 10 & 1 \\
\hline
\end{tabular}

TABLE 1.2 GEOMETRICAL SPECIFICATIONS OF FLUID DOMAINS OF SPHE

\begin{tabular}{|c|c|c|}
\hline $\begin{array}{c}\text { Length of SPHE } \\
(\mathbf{m m})\end{array}$ & $\begin{array}{c}\text { Inner pipe Diameter } \\
(\mathbf{m m})\end{array}$ & $\begin{array}{c}\text { Outer pipe Diameter } \\
(\mathbf{m m})\end{array}$ \\
\hline 518 & 32 & 52 \\
\hline
\end{tabular}




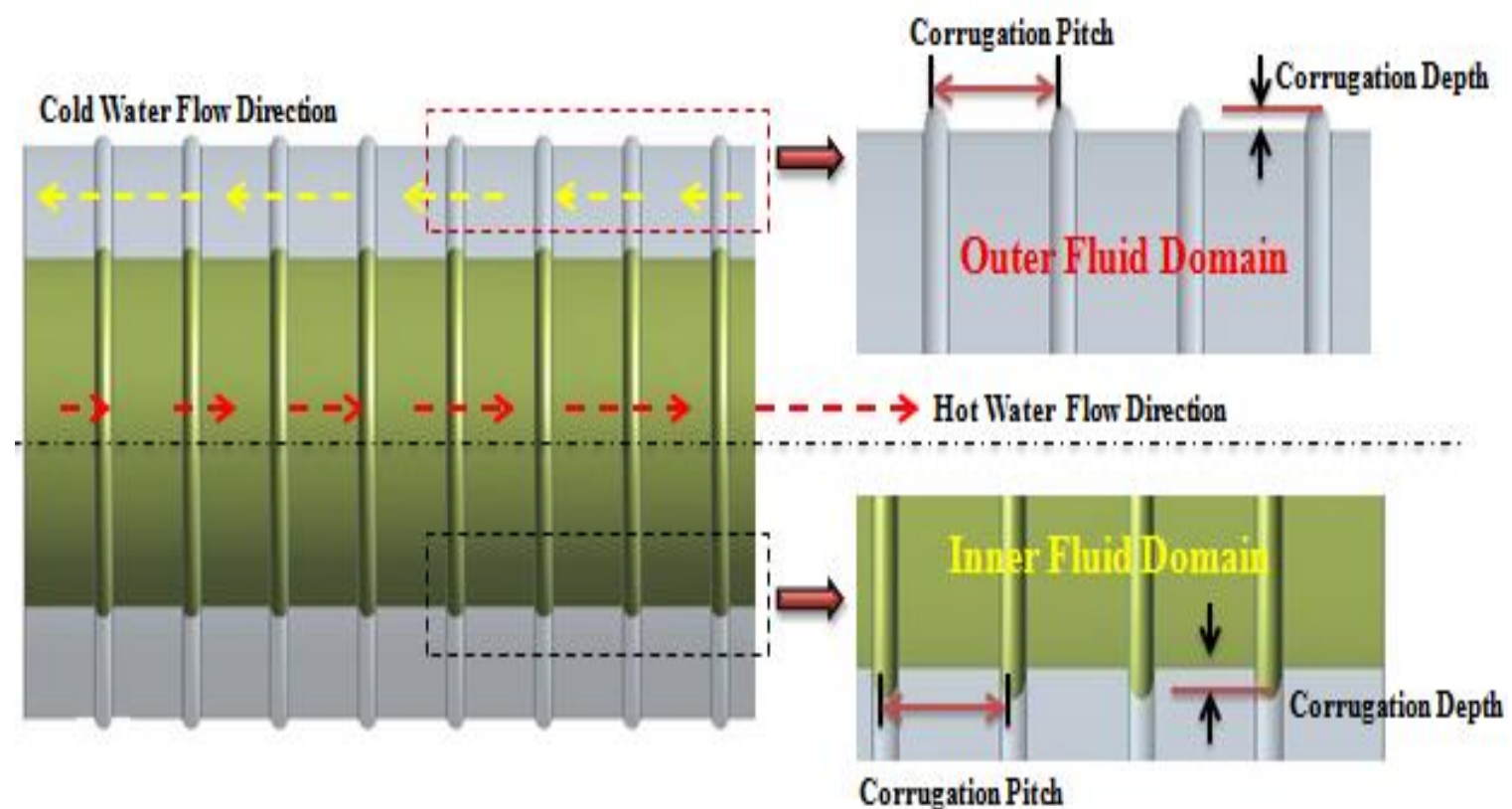

Fig.2Structural Details of fluid domains

Fig. 2 depicts the various geometrical parameters of a corrugated structure as well as the fluid flow direction.

Fig.3 shows the cut section view of the double pipe heat exchanger depicting the corrugations and their mutual interaction surfaces.

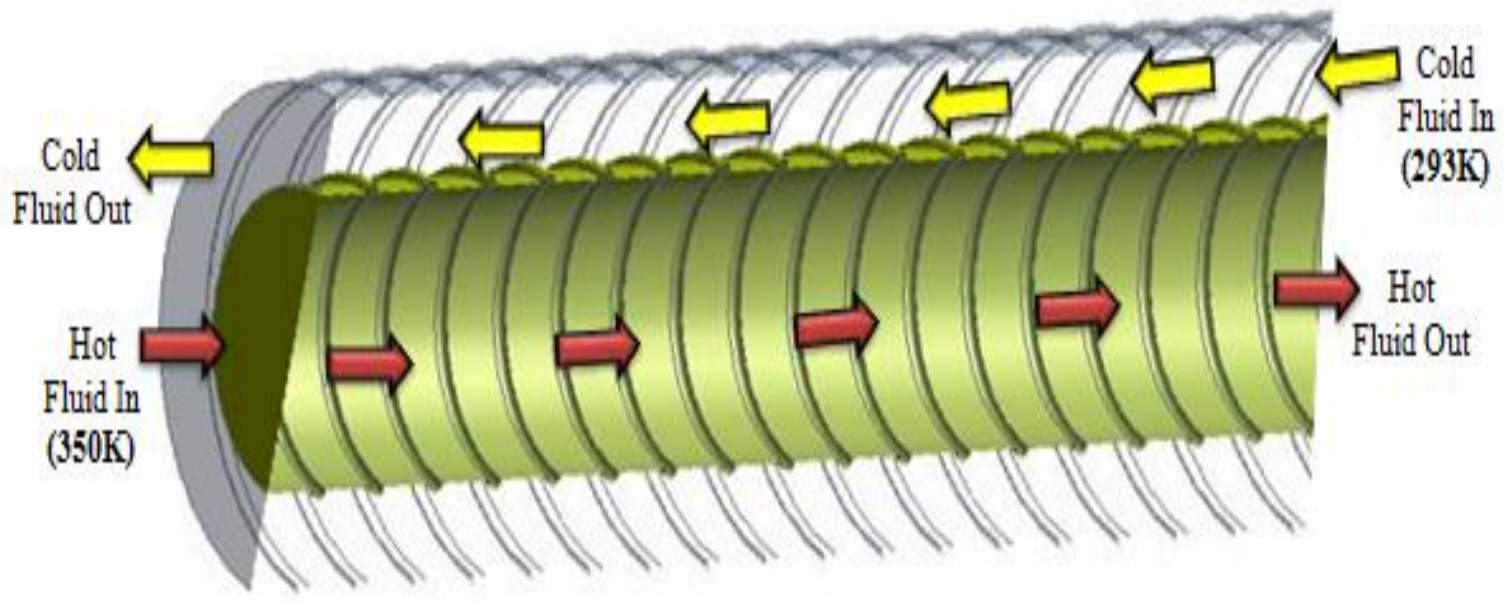

Fig.3Cross-sectional View of the corrugated fluid domains

\section{b)Discretization of modeled geometry}

One of the most important parts in the analysis of DPHE is the discretization of a modeled geometry. It has been done meticulously so that the end outcome would be perfect. Meshing or Discretization is a timeconsuming technique. In this research, a hexagonal mesh was stimulated, and the number of elements after meshing was discovered to be 403992. Hexagonal meshing (Fig.4) is done as it can generate more accurate results when the flow directions are known. Therefore, the entire fluid domain has been discretized with hexagonal medium size meshing. 


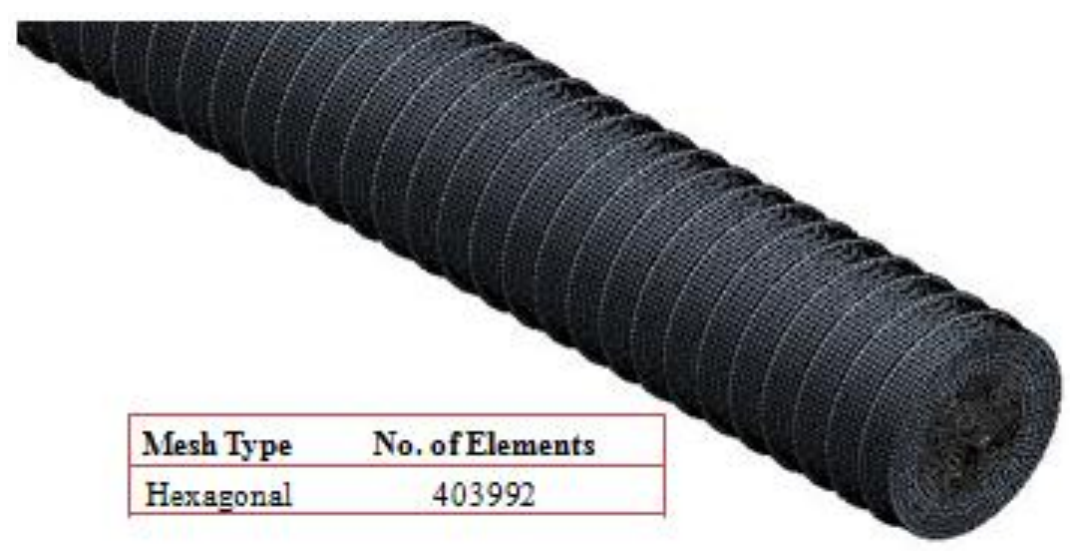

Fig.4Meshed Geometry with Medium Size

\section{c)Grid independency test}

In order to test the independency of the meshing, grid independency test has been performed using ANSYS FLUENT 15.0. Meshing has been done with coarse (Fig.5), medium (Fig. 4) and fine size(Fig. 6) and it has been found that for medium (403992) and fine (403992) meshing the number of elements do not change and a significant increase has been observed when it is done from coarse (307843) to medium (403992). This implies the results can be obtained with medium mesh size, therefore there is no need to mesh the fluid domains through fine mesh size.

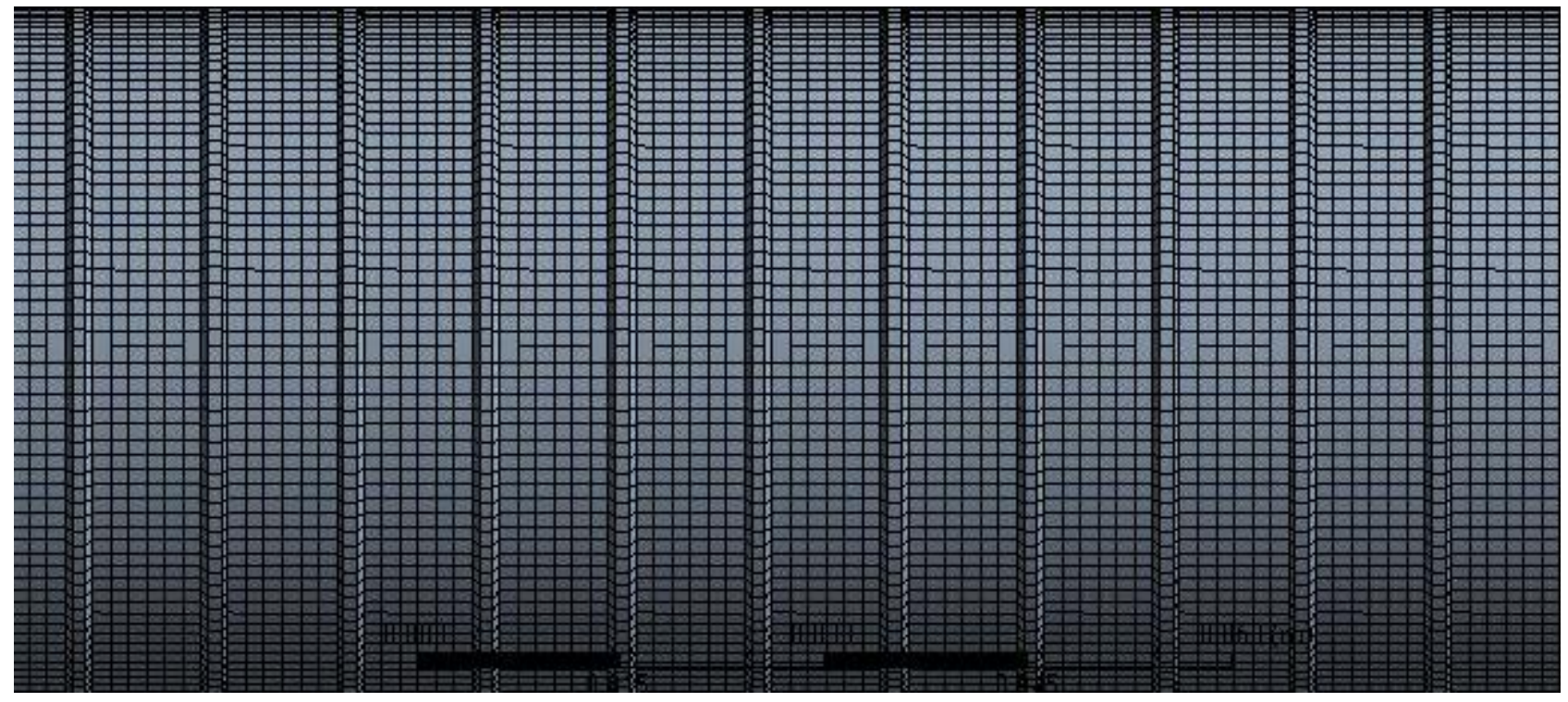

Fig.5Meshed Geometry with Coarse size 


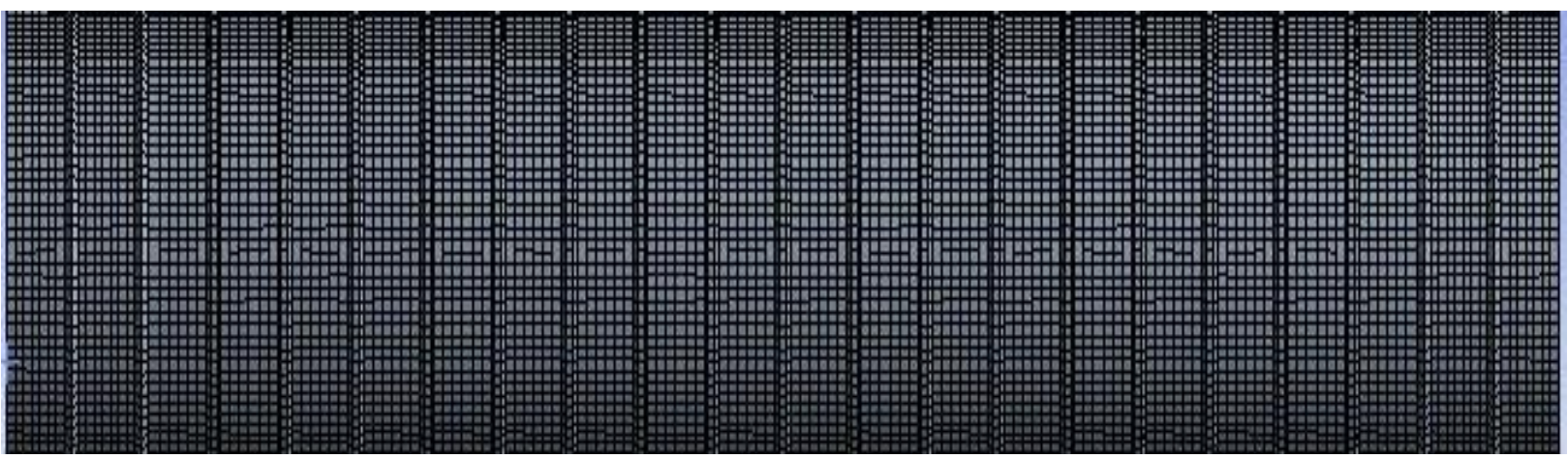

\section{Fig.6Meshed Geometry with Fine size}

\subsection{Solver Settings}

After completing the pre-processing, then the actual analysis has been performed for both smooth and corrugated pipe in the ANSYS FLUENT 15.0. The various steps followed in solving the problem till the solution is converged are explained below:

\section{a) Fluid Properties}

In the FLUENT interface, first of all there is a need to define the fluid properties for the inner and outer corrugated fluid domain of DPHE. As in the inner domain hot water at $350 \mathrm{~K}$ is entering therefore the properties at $350 \mathrm{~K}$ of water are inserted in the interface (Fig.7). In case of outer fluid domain, the properties of water at $293 \mathrm{~K}$ (Fig.8) are inserted in the interface. The table 1.3 below shows the various input properties of hot and cold water.

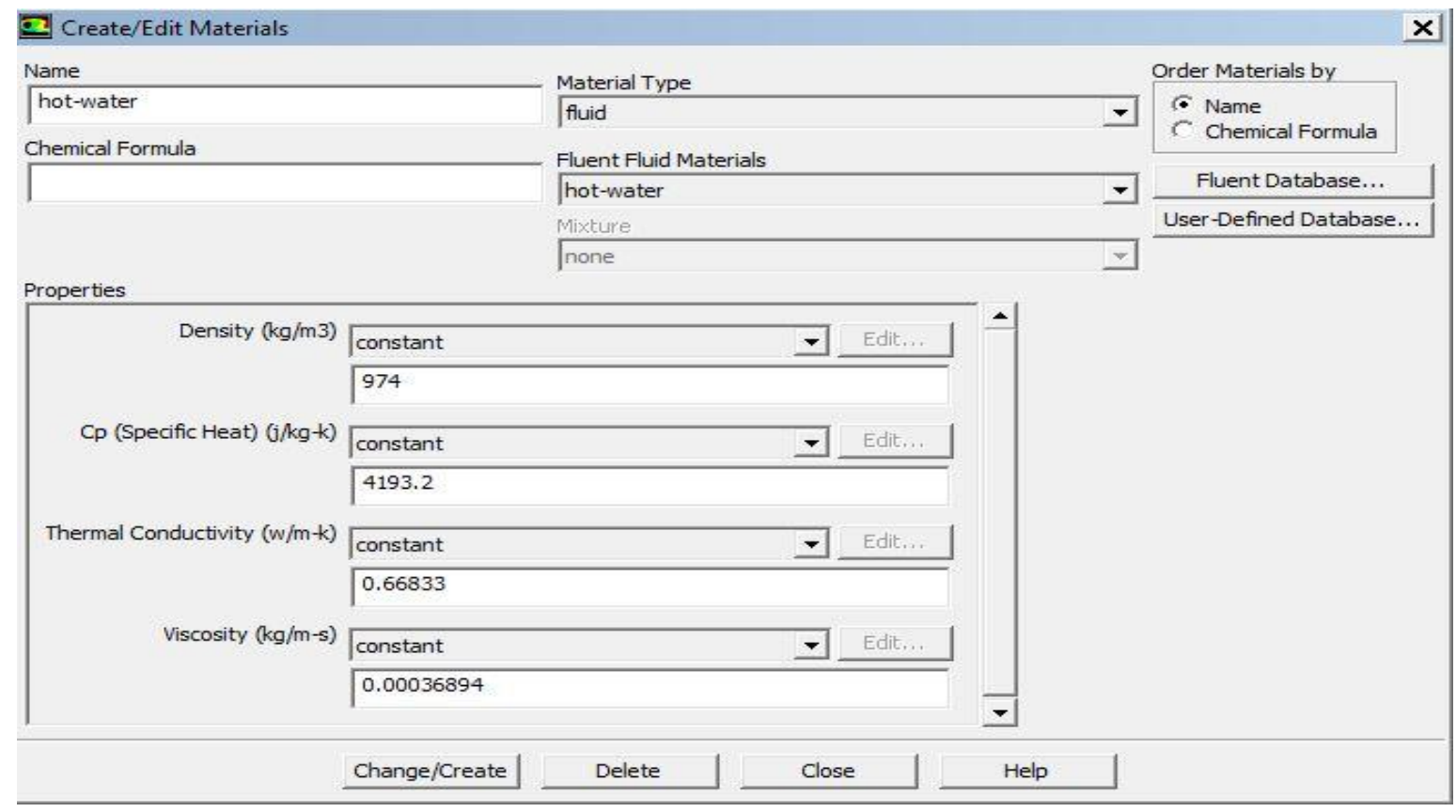

Fig.7 Properties of hot water at 350K 


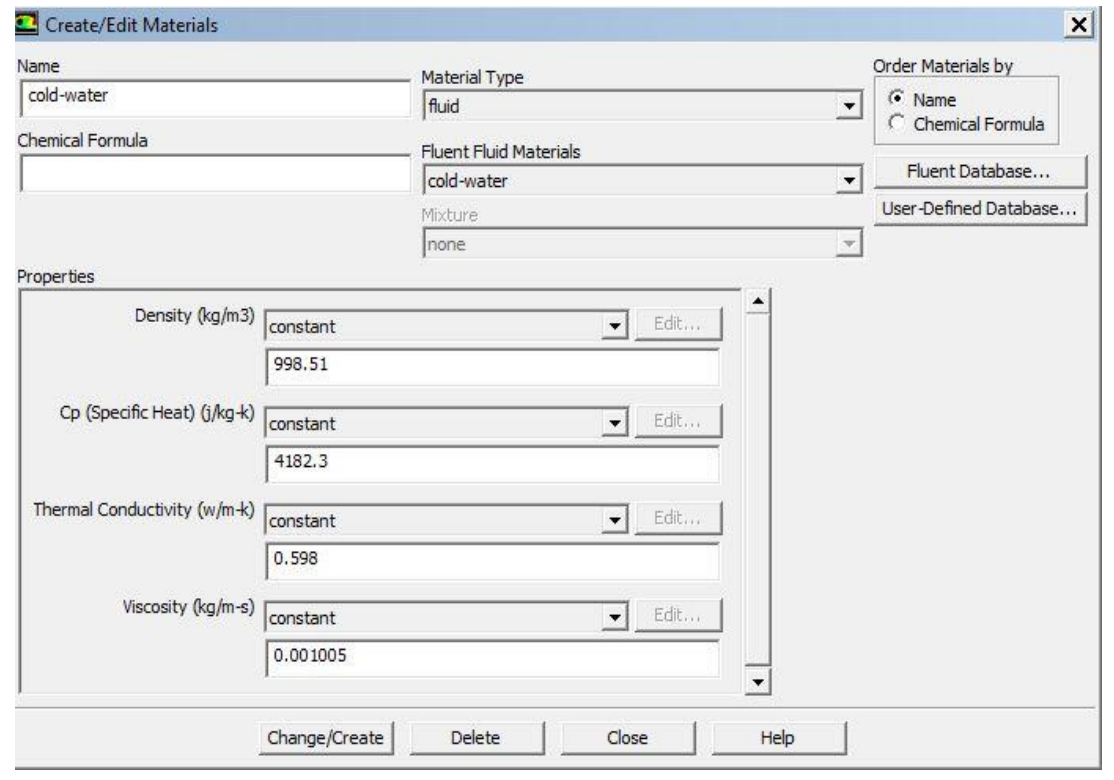

Fig.8 Properties of cold water at 293K

TABLE 1.3 INPUT CHARACTERISTICS OF HOT AND COLD WATER

\begin{tabular}{|c|c|c|c|c|c|}
\hline Properties & $\begin{array}{c}\text { Temperature } \\
(\mathbf{K})\end{array}$ & $\begin{array}{c}\text { Viscosity } \\
(\mathbf{k g} / \mathbf{m s})\end{array}$ & $\begin{array}{c}\text { Density } \\
\left(\mathbf{k g} / \mathbf{m}^{\mathbf{3}}\right)\end{array}$ & $\begin{array}{c}\text { Specific heat } \\
(\mathbf{J} / \mathbf{k g K})\end{array}$ & $\begin{array}{c}\text { Thermal } \\
\text { conductivity } \\
(\mathbf{W} / \mathbf{m K})\end{array}$ \\
\hline Hot water & 350 & 0.00036894 & 974 & 4193.2 & 0.66833 \\
\hline Cold water & 293 & 0.001005 & 998.51 & 4182.3 & 0.5980 \\
\hline
\end{tabular}

\section{b) Mathematical Models}

In order to perform Thermohydraulic Analysis of Double Pipe Heat Exchanger with Corrugated Tubes, generally five equations are need to be solve and these are continuity equation, x-momentum, y-momentum, z-momentum equations and energy equation, as given below from equation [1.1] to equation [1.5] These equations can be written in the mathematical form as given below:

Continuity Equation

$\frac{\partial \rho}{\partial t}+\frac{\partial(\rho u)}{\partial x}+\frac{\partial(\rho v)}{\partial y}+\frac{\partial(\rho w)}{\partial z}=0$

Momentum Equation

$\rho \frac{\partial u}{\partial t}+\rho u \frac{\partial u}{\partial x}+\rho v \frac{\partial u}{\partial y}+\rho w \frac{\partial u}{\partial z}=-\frac{\partial \hat{p}}{\partial x}+\mu\left|\frac{\partial^{2} u}{\partial x^{2}}+\frac{\partial^{2} u}{\partial y^{2}}+\frac{\partial^{2} u}{\partial z^{2}}\right|$ 
$\rho \frac{\partial v}{\partial t}+\rho u \frac{\partial v}{\partial x}+\rho v \frac{\partial v}{\partial y}+\rho w \frac{\partial v}{\partial z}=-\frac{\partial \hat{p}}{\partial y}+\mu\left|\frac{\partial^{2} v}{\partial x^{2}}+\frac{\partial^{2} v}{\partial y^{2}}+\frac{\partial^{2} v}{\partial z^{2}}\right|$

$\underbrace{\rho \frac{\partial w}{\partial t}}+\rho u \underbrace{u \frac{\partial w}{\partial x}+\rho v \frac{\partial w}{\partial y}+\rho w \frac{\partial w}{\partial z}}=\underbrace{-\frac{\partial \hat{p}}{\partial z}}+\underbrace{\mid \frac{\partial^{2} w}{\partial x^{2}}+\frac{\partial^{2} w}{\partial y^{2}}+\frac{\partial^{2} w}{\partial z^{2}}} \mid$,

Local

Acceleration

Convection

Pressure gradient

Viscous terms

Energy Equation

$$
\begin{aligned}
& \left.\frac{\partial\left(E_{t}\right)}{\partial t}+\frac{\partial\left(u E_{t}\right)}{\partial x}+\frac{\partial\left(v E_{t}\right)}{\partial y}+\frac{\partial\left(w E_{t}\right)}{\partial z}=-\frac{\partial(u p)}{\partial x}-\frac{\partial(v p)}{\partial y}-\frac{\partial(w p)}{\partial z}-\frac{1}{\operatorname{Re} \operatorname{Pr}} \frac{\partial q_{x}}{\partial x}-\frac{\partial q_{y}}{\partial y}-\frac{\partial q_{z}}{\partial z}\right\rfloor \\
& +\frac{1}{\operatorname{Re}} \frac{\partial}{\partial x}\left(u \tau_{x x}+v \tau_{x y}+w \tau_{x z}\right)+\frac{\partial}{\partial y}\left(u \tau_{x y}+v \tau_{y y}+w \tau_{y z}\right)+\frac{\partial}{\partial z}\left(u \tau_{x z}+v \tau_{y z}+w \tau_{z z}\right) \mid
\end{aligned}
$$

In order to investigate heat transfer and flow analysis in corrugated DPHE, these equations are required to be solved. To solve these equations, Realizable 2 equation k-epsilon viscous model has been used as shown in Fig.9.

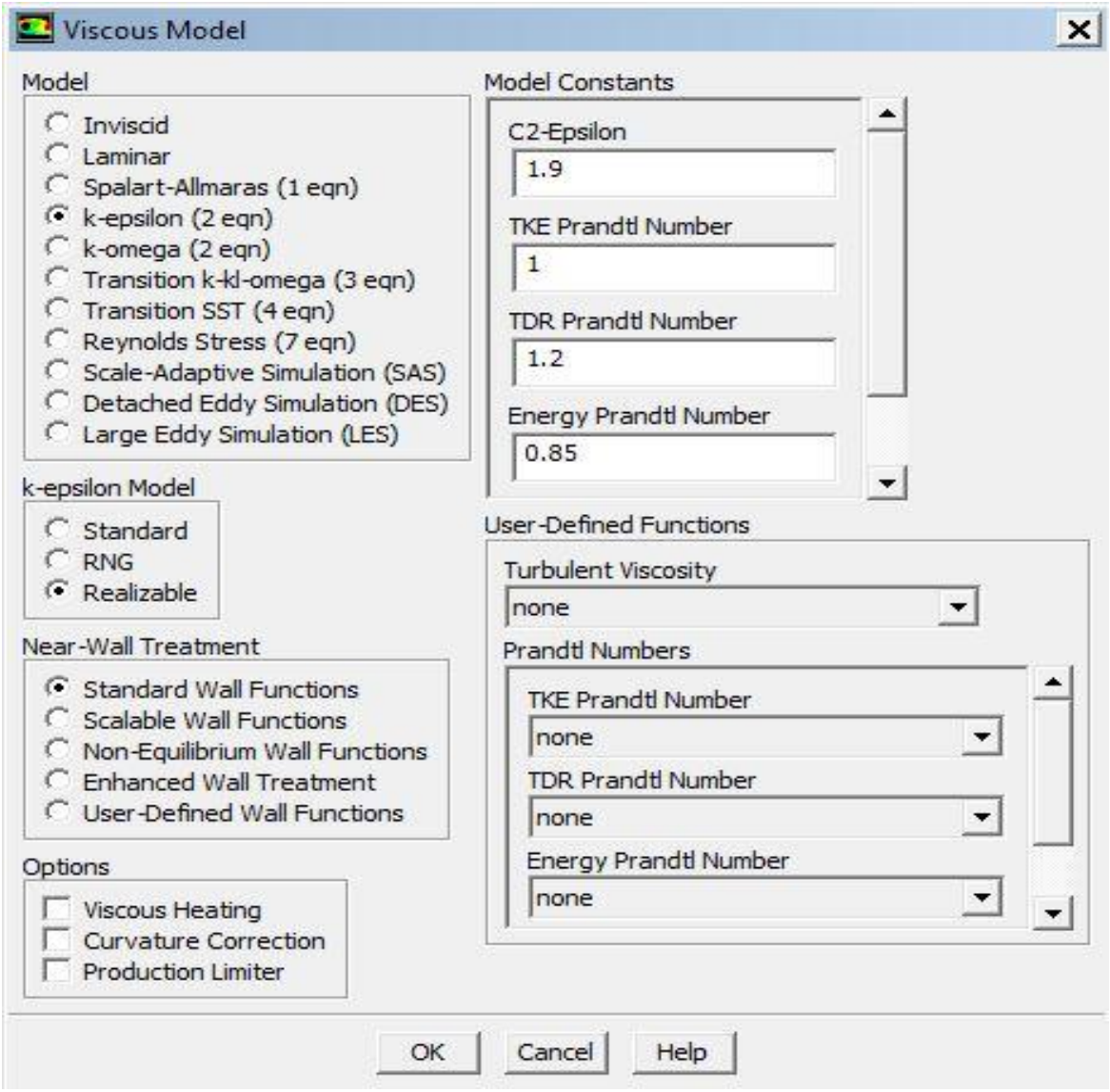

Fig.9 Viscous Models used in Computational Study of DPHE 


\section{c) Boundary Conditions}

The boundary conditions used in this analysis are available inFig. 10 to Fig 13and table 1.4. For pressure outlet boundary condition, the gauge pressure is $0 \mathrm{~Pa}$ as shown in Fig.12and Fig.13

\section{TABLE 1.4DIFFERENT INLET AND OUTLET BOUNDARY CONDITIONS FOR HOT AND COLD WATER}

\begin{tabular}{|c|c|c|c|c|c|c|c|}
\hline Water & \multicolumn{5}{|c|}{$\begin{array}{c}\text { Inlet Mass Flow Rate } \\
(\mathrm{kg} / \mathbf{s})\end{array}$} & $\begin{array}{c}\text { Temperature } \\
(\mathbf{K})\end{array}$ & Outlet \\
\hline Hot & 0.05 & 0.06 & 0.07 & 0.08 & 0.09 & 350 & $\begin{array}{c}\text { Pressure } \\
\text { Outlet }\end{array}$ \\
\hline Cold & 0.03 & 0.035 & 0.045 & 0.055 & 0.065 & 293 & $\begin{array}{c}\text { Pressure } \\
\text { Outlet }\end{array}$ \\
\hline
\end{tabular}

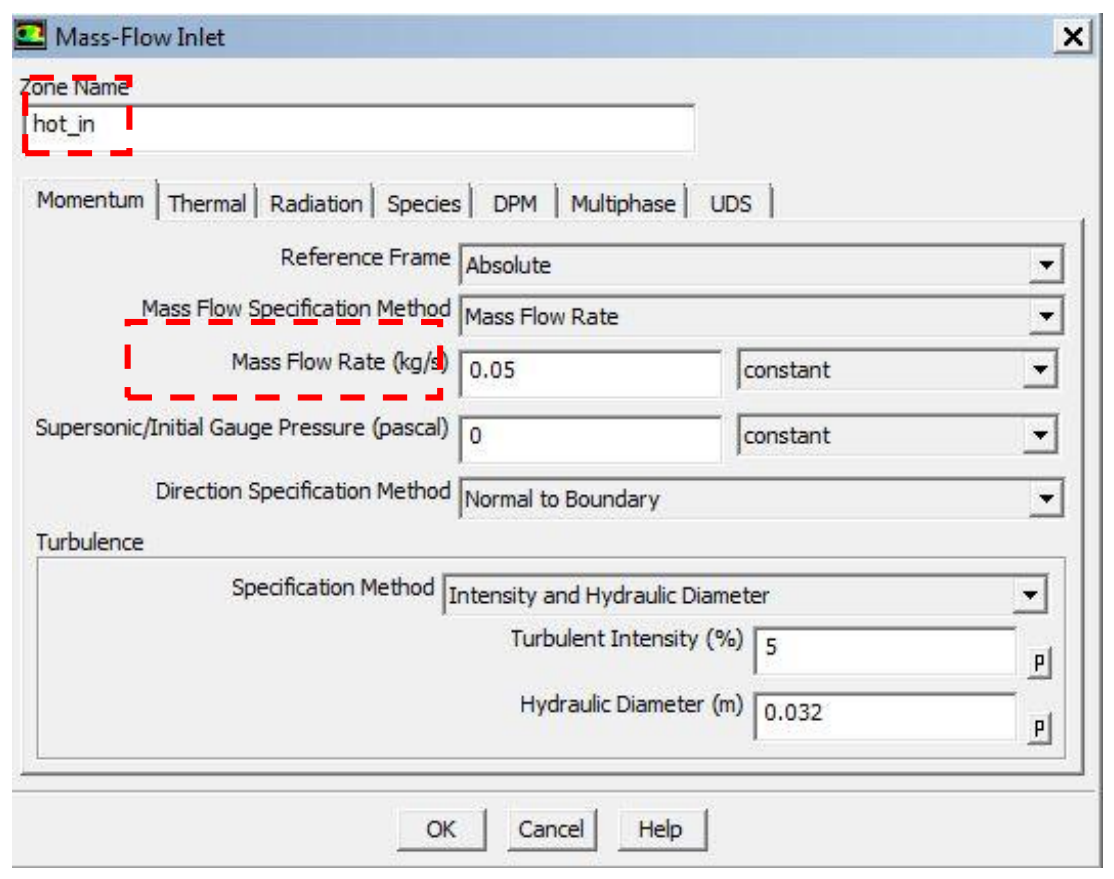

Fig.10Hot fluid inlet boundary condition 


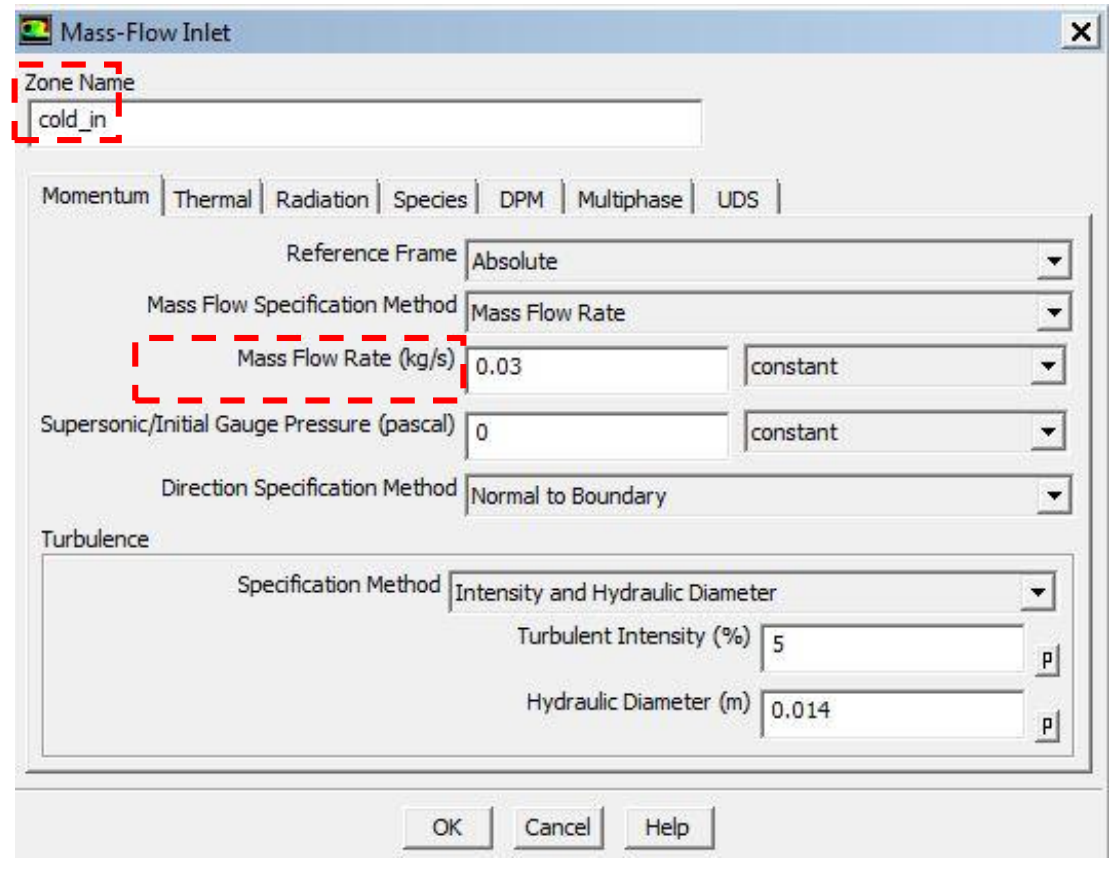

Fig.11Cold fluid inlet boundary condition

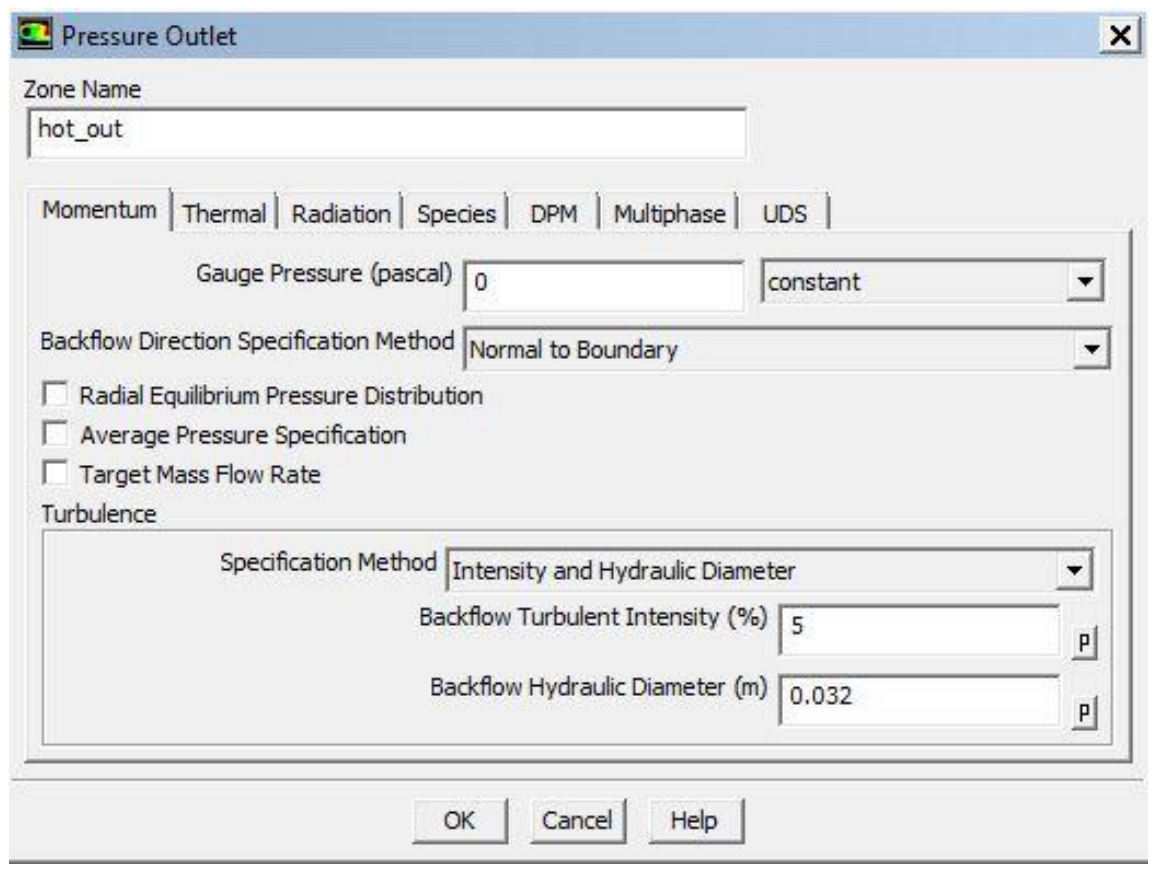

Fig.12 Pressure Outlet boundary condition for hot fluid 


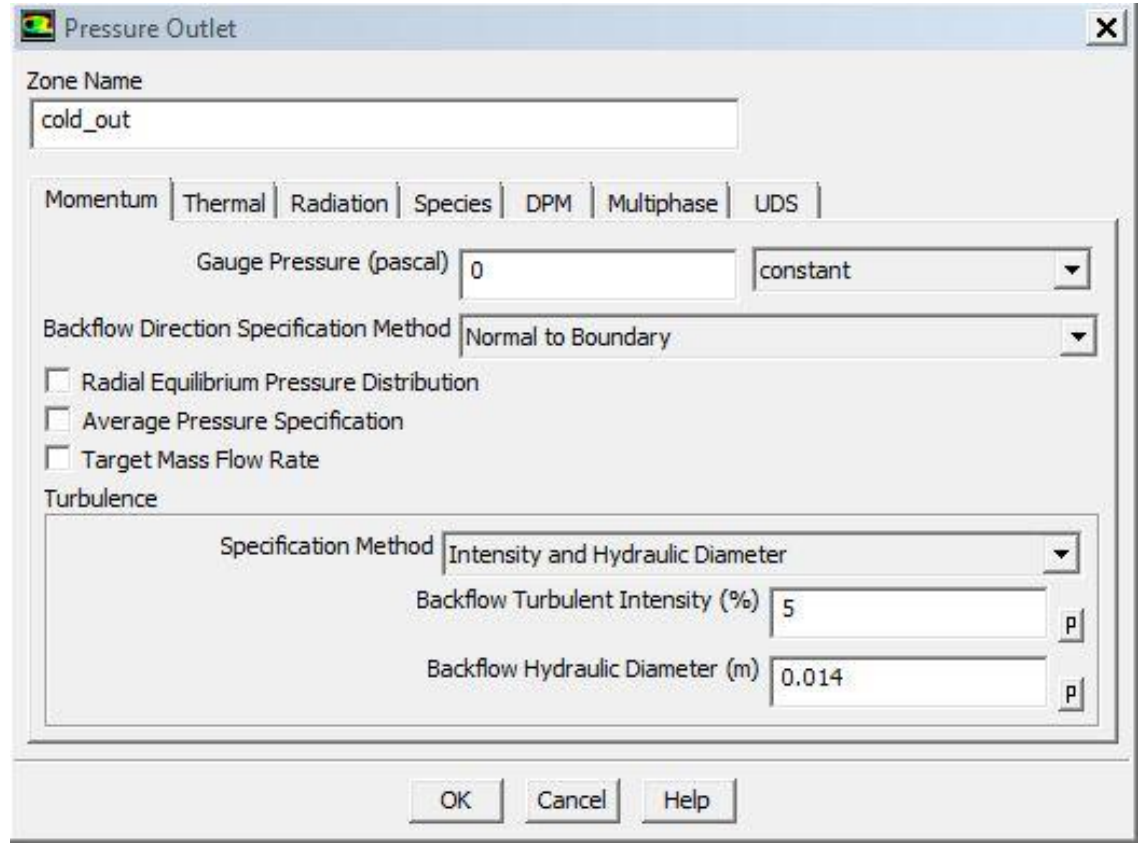

Fig.13Pressure Outlet boundary condition for cold fluid

d) Solution Initialization and Calculation

Hybrid initialization has been used in order to initialize the solution.

\subsection{Post-Processing}

In order to evaluate the results, this phase known as post processing Interface has been conducted. The detailed analysis with regard to the decrease in pressure, pumping power required, temperature profiles, total heat transfer rates has been presented in next chapter under the section results and discussion

\section{Calculation}

Computational fluid dynamics study was performed on the geometries of both the Double pipe corrugated heat exchanger and the smooth double pipe heat exchanger built in ANSYS using ANSYS Fluent. The geometrical parameters for two different pipes were ascertained and the flow characteristics and other associated properties of water being used as a fluid were input in order to carry out the simulations. The boundary conditions were then defined as two different set of input mass flow rates each for the Concentric double corrugated pipe and Concentric double smooth pipe carrying fluids in inner and outer pipes at different temperatures. The outputs in terms of pressure drop, variation of velocity, increase in heat transfer and others were further used in the analysis to find out various dimensionless numbers. The flow and heat transfer characteristics of the two kinds of pipes were thus ascertained.

\section{1 analytical calculation}

The heat transport and flow properties of the fluid in both conduits were determined using the results of computational fluid dynamics. The section ahead represents the mathematical expressions those have been used to make the data available more meaningful in order to evaluate friction factor, Reynold's number, pressure drop, pumping power and Nusselt number. 


\section{Calculation for Pumping Power}

The pressure drop numbers and volumetric flow rate are used to calculate the pumping power required to pump the water through the corrugated pipe. We know work done per unit time is power,

$\mathrm{W}=\frac{\mathrm{F} . \mathrm{S}}{\mathrm{t}}$

$$
\begin{aligned}
& \mathrm{F}=\text { Applied force } \\
& \mathrm{S}=\text { displacement produced by the force } \\
& \mathrm{t}=\text { time of application of force }
\end{aligned}
$$

Multiplying and dividing by area

$\mathrm{W}=\frac{\mathrm{FAs}}{\mathrm{At}}$

Or $\mathrm{W}=\Delta \mathrm{p} \frac{\mathrm{V}}{\mathrm{t}}$

$\mathrm{W}=\Delta \mathrm{p} \dot{\mathrm{V}}$

Where $\dot{\mathrm{V}}=\mathrm{A} \times \mathrm{v}_{\text {avg }}$ is volume flow rate $\left(\mathrm{m}^{3} / \mathrm{sec}\right)$

$$
\mathrm{A}=\text { area of cross-section of the pipe }\left(\mathrm{m}^{2}\right) \text {. }
$$

$\Delta p=$ Pressure Drop $(\mathrm{Pa})$

The pumping power calculated by using equation 4 above for DPCHE and SPHE for both the cases of hot and cold fluid are tabled below in tables 1.5 to 1.8. From the tables it is clear that higher the pressure drop and volume flow rate larger power would be required to pump the fluid. Thus, in order to reduce the fluid transfer costs, the pressure drops in the conduit have to be kept minimum.

Table 1.5 depicts the values of pumping power as ascertained from Pressure drop and Volume flow rate for Double Pipe Corrugated heat exchanger for fluid at higher temperature. The power required to pump the fluid increases with the increasing pressure drop and volume flow rate which in turn increases with mass flow rate.

TABLE 1.5 PUMPING POWER VALUES FOR DPCHE HOT WATER

\begin{tabular}{|c|c|c|c|}
\hline $\begin{array}{c}\text { Mass flow rate } \\
(\mathbf{k g} / \mathbf{s})\end{array}$ & $\begin{array}{c}\text { Pressure drop } \\
(\mathbf{P a})\end{array}$ & $\begin{array}{c}\text { Volume flow } \\
\text { rate } \\
(\mathbf{L} / \mathbf{m i n})\end{array}$ & $\begin{array}{c}\text { Pumping Power } \\
(\mathbf{W})\end{array}$ \\
\hline 0.05 & 3.5012 & 3.080 & $2.00 \mathrm{E}-04$ \\
\hline 0.06 & 4.4927 & 3.696 & $2.87 \mathrm{E}-04$ \\
\hline 0.07 & 5.5039 & 4.312 & $3.96 \mathrm{E}-04$ \\
\hline 0.08 & 6.7091 & 4.928 & $5.51 \mathrm{E}-04$ \\
\hline 0.09 & 7.9684 & 5.544 & $7.36 \mathrm{E}-04$ \\
\hline
\end{tabular}

Table 1.6 depicts the values of pumping power as ascertained from Pressure drop and Volume flow rate for 
Double Pipe Corrugated heat exchanger for fluid at lower temperature. Comparing both the tables 1.5 and 1.6 it can be ascertained that owing to higher mass flow rate of the Hot fluid the volume flow rates for the same are also higher which further increases the power required to pump the fluid as compared to cold fluid flowing through the same conduit.

TABLE 1.6 PUMPING POWER VALUES FOR DPCHE COLD WATER

\begin{tabular}{|c|c|c|c|}
\hline $\begin{array}{c}\text { Mass flow rate } \\
(\mathbf{k g} / \mathbf{s})\end{array}$ & $\begin{array}{c}\text { Pressure drop } \\
(\mathbf{P a})\end{array}$ & $\begin{array}{c}\text { Volume flow } \\
\text { rate } \\
(\mathbf{L} / \mathbf{m i n})\end{array}$ & $\begin{array}{c}\text { Pumping Power } \\
(\mathbf{W})\end{array}$ \\
\hline 0.030 & 2.8163 & 1.802 & $0.85 \mathrm{E}-04$ \\
\hline 0.035 & 3.2649 & 2.103 & $1.14 \mathrm{E}-04$ \\
\hline 0.045 & 4.005 & 2.704 & $1.80 \mathrm{E}-04$ \\
\hline 0.055 & 5.0496 & 3.305 & $2.78 \mathrm{E}-04$ \\
\hline 0.065 & 6.3005 & 3.906 & $4.10 \mathrm{E}-04$ \\
\hline
\end{tabular}

From the comparison of table 1.5 with table 1.7 it is further seen that although the volume flow rates are same for hot fluid in SPHE and DPCHE the pressure drops are higher in DPCHE as expected due to corrugations. These higher pressure drops lead to higher pumping power for DPCHE.

TABLE 1.7 PUMPING POWER VALUES FOR SPHE HOT WATER

\begin{tabular}{|c|c|c|c|}
\hline $\begin{array}{c}\text { Mass flow rate } \\
(\mathbf{k g} / \mathbf{s})\end{array}$ & $\begin{array}{c}\text { Pressure drop } \\
(\mathbf{P a})\end{array}$ & $\begin{array}{c}\text { Volume flow rate } \\
(\mathbf{L} / \mathbf{m i n})\end{array}$ & $\begin{array}{c}\text { Pumping Power } \\
(\mathbf{W})\end{array}$ \\
\hline 0.05 & 2.972 & 3.080 & $1.53 \mathrm{E}-04$ \\
\hline 0.06 & 3.7977 & 3.696 & $2.34 \mathrm{E}-04$ \\
\hline 0.07 & 4.5827 & 4.312 & $3.29 \mathrm{E}-04$ \\
\hline 0.08 & 5.3864 & 4.928 & $4.42 \mathrm{E}-04$ \\
\hline 0.09 & 6.2095 & 5.544 & $5.74 \mathrm{E}-04$ \\
\hline
\end{tabular}

Similar trend can be observed from table 1.6 and 1.8 for cold fluids flowing in above two kinds of conduit wherein the pressure drop in corrugated pipes are higher for the same volume flow rate leading to more power requirement. Also comparing table 1.7 and table 1.8, it can be ascertained that owing to higher mass flow rate of the Hot fluid the volume flow rates for the same are also higher which further increases the power required to pump the fluid as compared to cold fluid flowing through the same conduit. 
TABLE 1.8 PUMPING POWER VALUES FOR SPHE COLD WATER

\begin{tabular}{|c|c|c|c|}
\hline $\begin{array}{c}\text { Mass flow rate } \\
(\mathbf{k g} / \mathbf{s})\end{array}$ & Pressure drop $(\mathbf{P a})$ & $\begin{array}{c}\text { Volume flow rate } \\
(\mathbf{L} / \mathbf{m i n})\end{array}$ & $\begin{array}{c}\text { Pumping Power } \\
(\mathbf{W})\end{array}$ \\
\hline 0.030 & 1.8122 & 1.802 & $0.54 \mathrm{E}-04$ \\
\hline 0.035 & 2.1415 & 2.103 & $0.75 \mathrm{E}-04$ \\
\hline 0.045 & 2.8166 & 2.704 & $1.27 \mathrm{E}-04$ \\
\hline 0.055 & 3.5051 & 3.305 & $1.93 \mathrm{E}-04$ \\
\hline 0.065 & 4.2057 & 3.906 & $2.74 \mathrm{E}-04$ \\
\hline
\end{tabular}

2.2 ANALYSIS OF DOUBLE PIPE CORRUGATED HEAT EXCHANGER (DPCHE)

The various parameters like pressure drop, exit temperature, heat transfer, obtained from CFD have been used in the previous section to find out the flow and heat transfer parameters involved in heat and mass transfer problems in fluid conduits. The section ahead depicts the plots of these parameters so as to analyze their variation in the same conduit as well with the other concentric conduit carrying the two kinds of fluids in Double Pipe Corrugated Heat Exchanger.

\section{Pressure Drop and pumping power Analysis for DPCHE}

In the present study, pressure drop analysis has been done in order to evaluate the turbulent flow effects when hot water is flowing in the inner corrugated pipe of double pipe heat exchanger and the cold water in outer annulus region. Fig. 14shows the contour plot for total pressure in DPCHE.

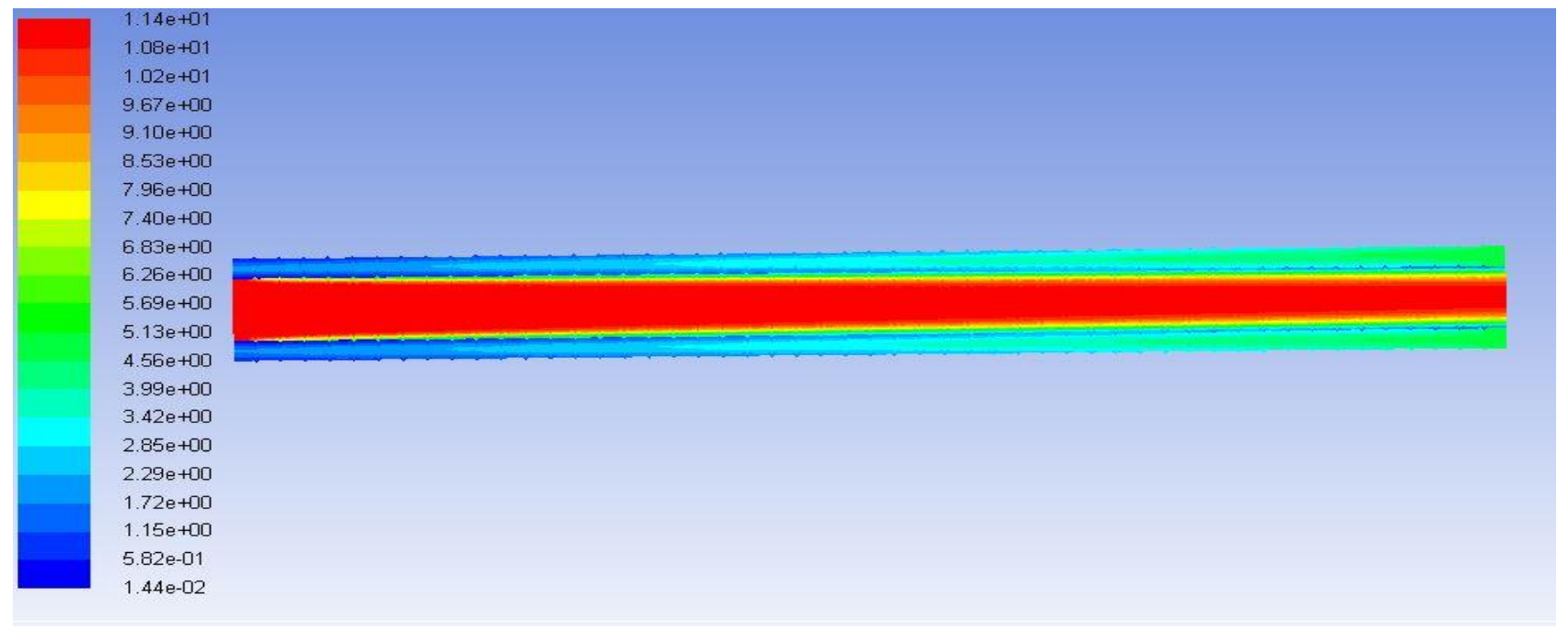

Fig. 14 Contours plot of total pressure at a section of DPCHE

Fig. 15 and Fig. 16 shows pumping power required to pump the hot and cold fluid. It can be noticed that the pumping power is found to increase with the increase in mass flow rate for both hot and cold fluid. This is attributed to the fact that with the increase in mass flow rate the pressure drop increases which will increase the pumping power 


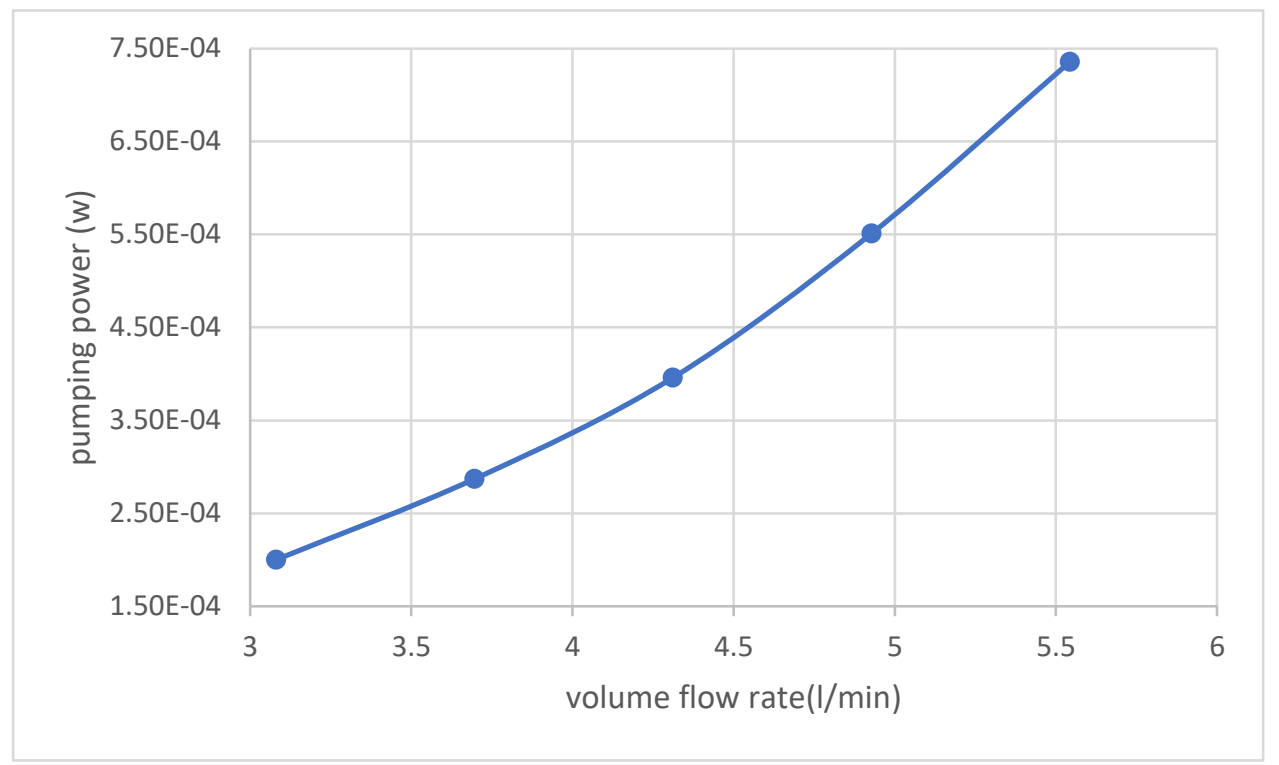

Fig. 15variation for hot water in DPCHE

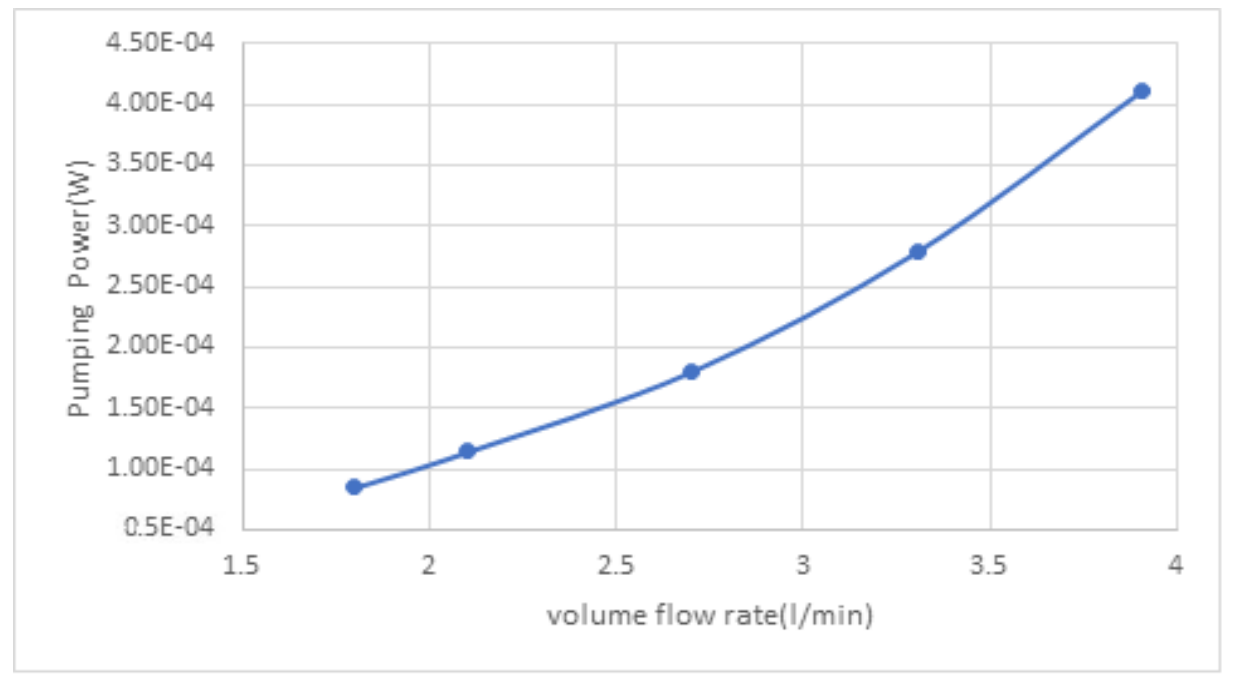

Fig. 16variation for cold water in DPCHE

\subsection{ANALYSIS FOR SMOOTH PIPE HEAT EXCHANGER (SPHE)}

The CFD analysis was also conducted for smooth pipe heat exchanger, for the same length and similar geometric parameters for both inner and outer pipes as taken for corrugated pipe. The results obtained have been tabled in section 5.1. The section below represents the results in graphical form for comparison within the given conduit at varying inputs as well as between the inner and outer conduits of a Smooth Pipe Heat Exchanger.

\section{Pressure Drop and pumping power Analysis for SPHE}

In the present study, pressure drop analysis has been done in order to evaluate the turbulent flow effects when hot water is flowing in the inner pipe of double pipe smooth heat exchanger and the cold water in outer annulus region. Fig. 17 shows the contour plot for total pressure in SPHE. 


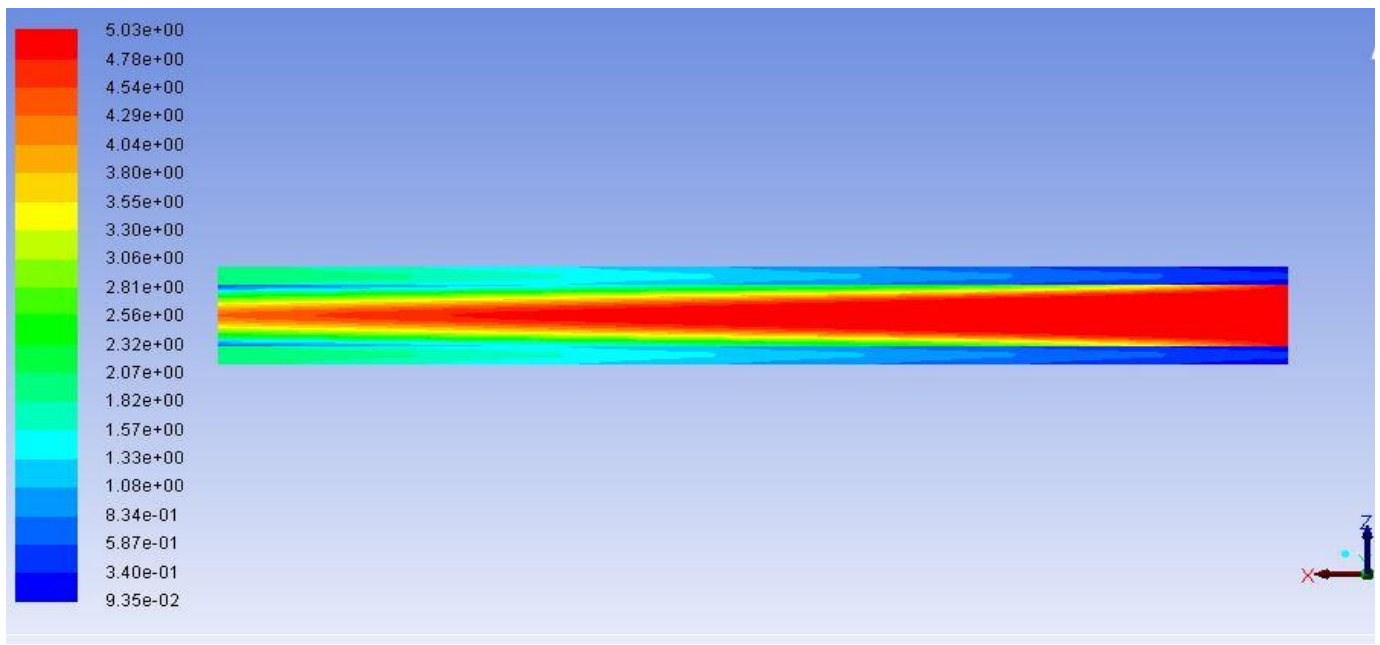

Fig. 17 Contours plot of total pressure at a section of SPHE

Fig. 18 and Fig. 19 shows pumping power required to pump the hot and cold fluid. It can be seen that the pumping power increases as the mass flow rate increases for both hot and cold fluid. This is due to the fact that when the mass flow rate rises, the pressure drop rises, resulting in a rise in the total power required to pump the fluid, resulting in a proportionate rise in pumping power.

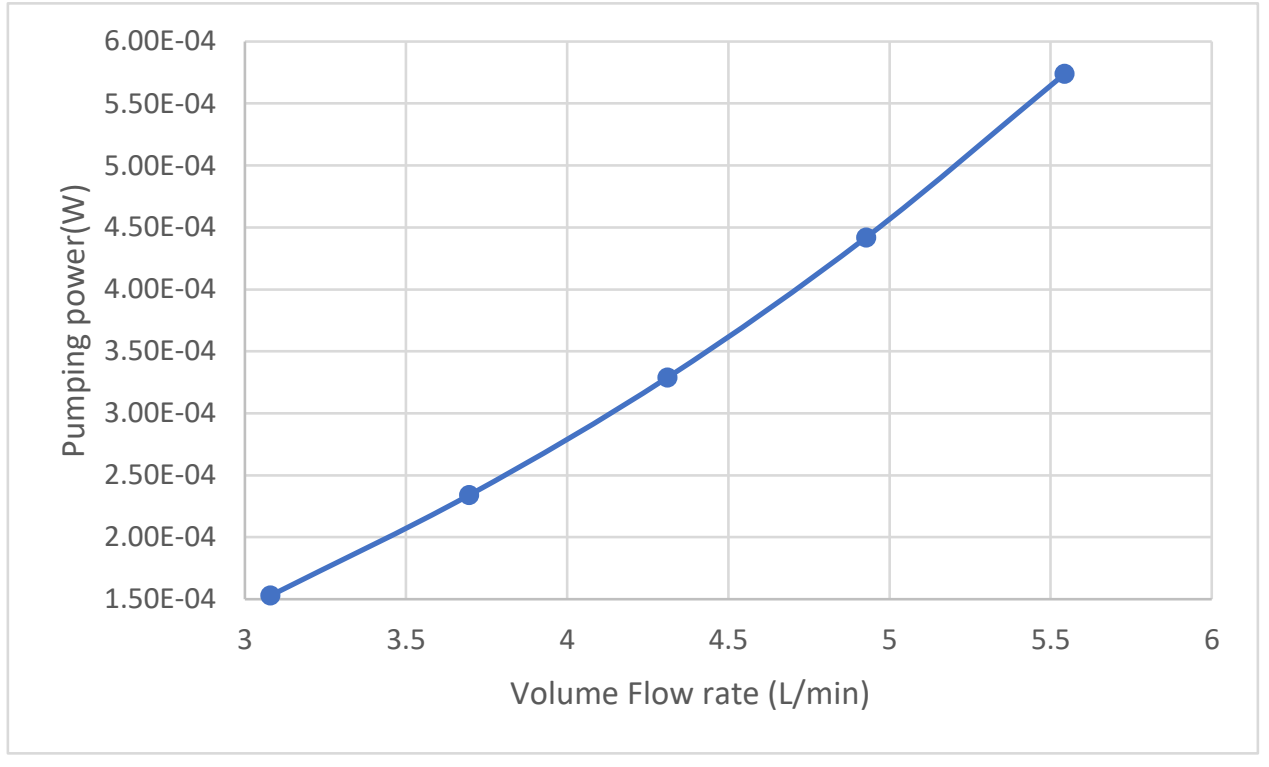

Fig 18variation for hot waterin SPHE 


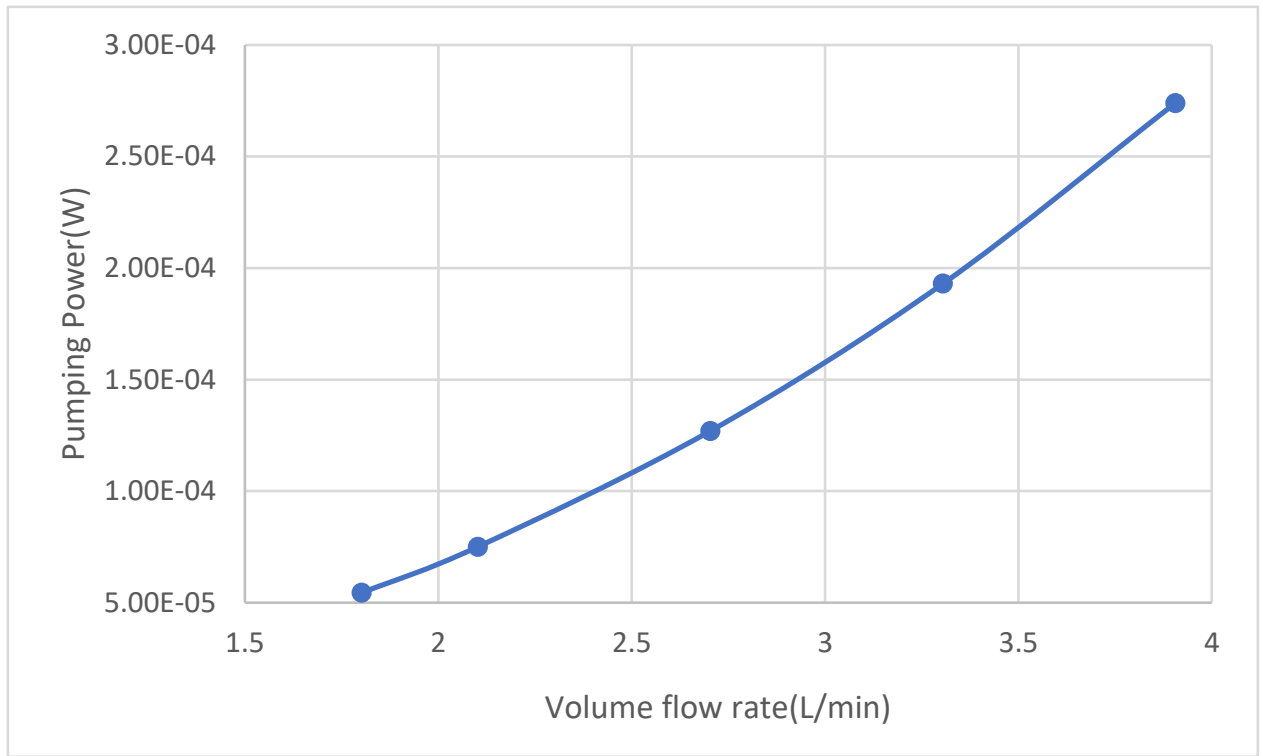

Fig 19variation for cold water in SPHE

\section{COMPARISON OF DOUBLE PIPE CORRUGATED HEAT EXCHANGER (DPCHE) AGAINST SMOOTH DOUBLE PIPE HEAT EXCHANGER (SPHE)}

The results obtained in the analysis of Double pipe corrugated heat exchanger(DPCHE) have been compared with a similar analysis on Smooth double pipe heat exchanger (SPHE) to adjudge the effects of corrugation on the heat exchange and pressure drop.

\section{Pumping power and flow ratecomparison}

The pumping power is found to be higher for DPCHE in comparison to SPHE which is attributed to the fact that for a given length and friction factor in DPCHE the pressure drop is higher owing to the effect of corrugation. The pressure drop also varies directly with the square of flow rate and thus pumping power is higher with increase in flow rate as is clear from the graphs plotted in fig. 20 and 21.

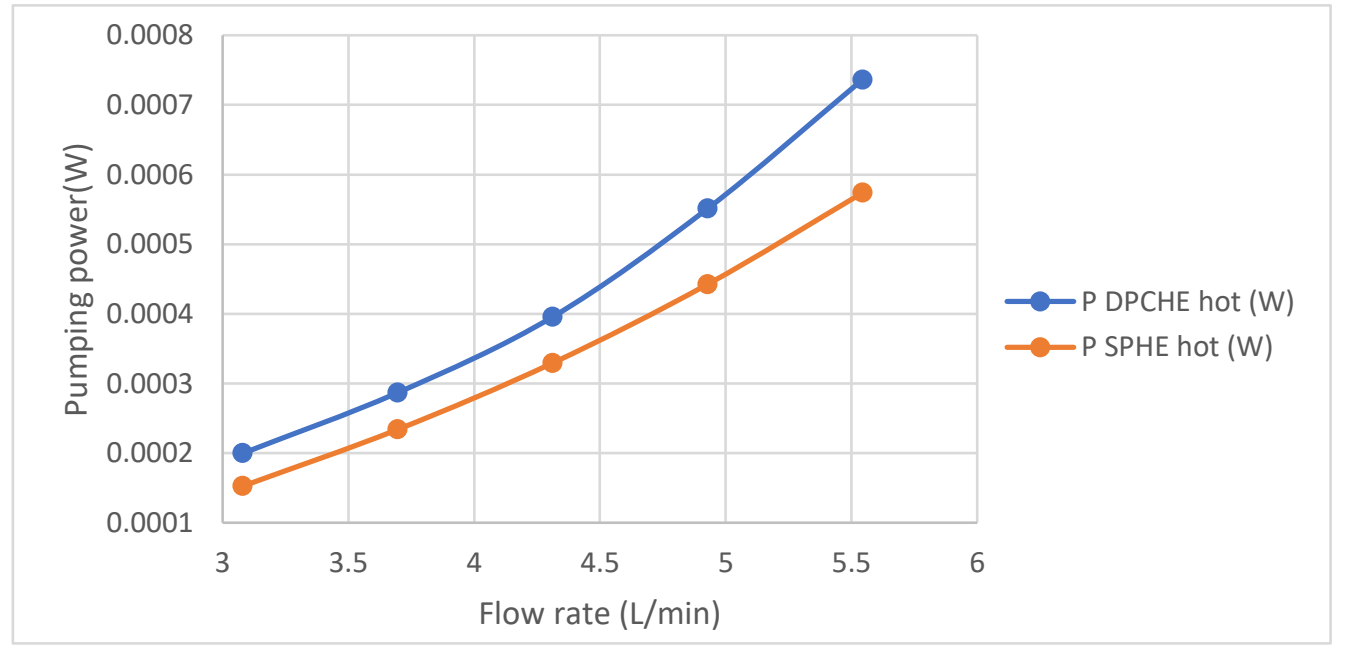

Fig. 20Comparison for hot waterin SPHE and DPCHE 


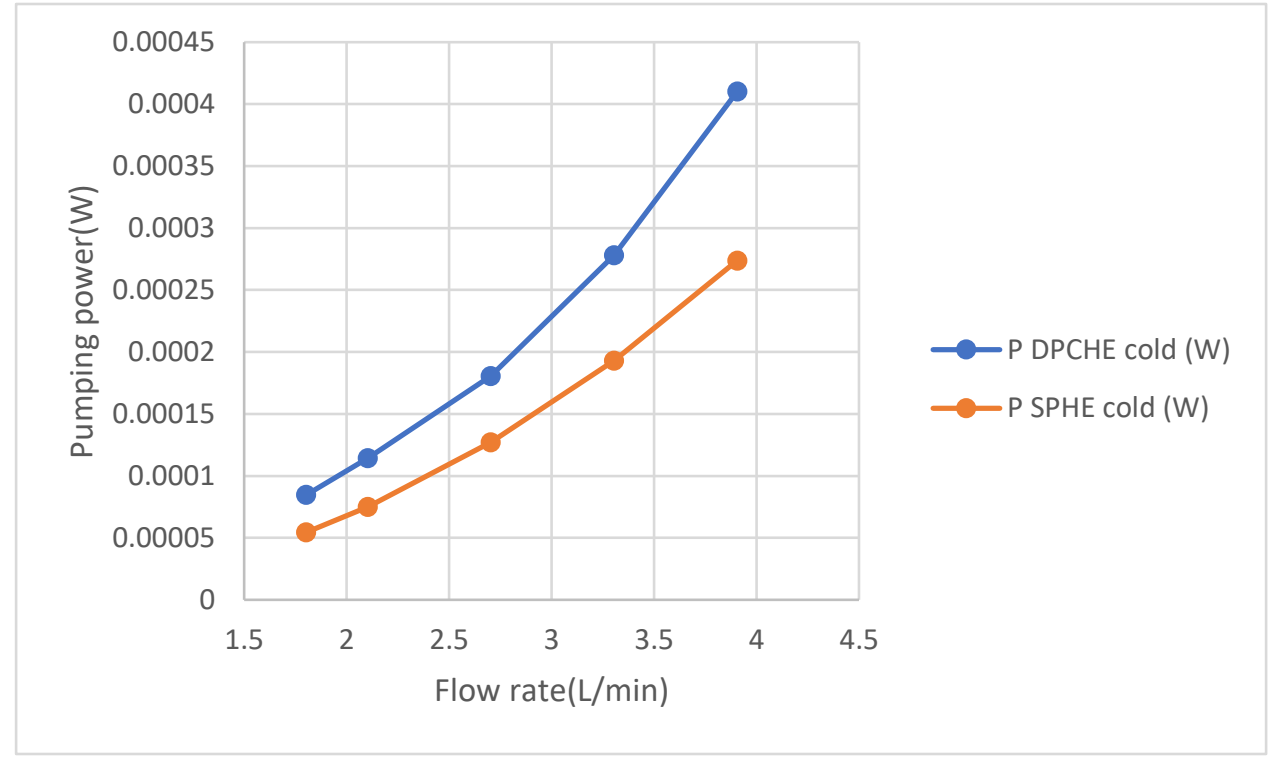

Fig. 21 variation for cold water in SPHE and DPCHE

\section{Conclusions}

In the present study, computational analysis on the corrugated double pipe heat exchanger has been done using ANSYS FLUENT 15.0. Corrugated fluid domains were created in the software and flow analysis has been done using Realizable 2 Equation Viscous Model after generating medium meshing. The analysis was performed by considering different mass flow rates at different temperatures

Certain conclusions are made and these are enlisted below:

- It can be concluded that there is a pressure drop of 4-5Pa for a heat exchanger length of 518mm.

- It has been found that there is anincrease in pumping power with the increase in mass flow rate for the fluids.

\section{REFERENCES}

1. N. T. R. Kumar, P. Bhramara, B. Mulat, L. S. Sundar, M. K. Singh, and A. C. M. Sousa, "Heat transfer, friction factor and effectiveness analysis of Fe $3 \mathrm{O} 4$ / water nano fl uid fl ow in a double pipe heat exchanger with return bend," Int. Commun. Heat Mass Transf., vol. 81, pp. 155-163, 2017.

2. A. El Maakoul, A. Laknizi, S. Saadeddine, A. Ben Abdellah, M. Meziane, and M. El Metoui, "Numerical design and investigation of heat transfer enhancement and performance for an annulus with continuous helical baffles in a double-pipe heat exchanger," Energy Convers. Manag., vol. 133, pp. 76-86, 2017.

3. A. Alhusseny, A. Turan, and A. Nasser, "Rotating metal foam structures for performance enhancement of double-pipe heat exchangers," Int. J. Heat Mass Transf., vol. 105, pp. 124139, 2017.

4. K. Kamboj, G. Singh, R. Sharma, D. Panchal, and J. Hira, "Heat transfer augmentation in 
double pipe heat exchanger using mechanical turbulators," Heat Mass Transf. und Stoffuebertragung, pp. 1-15, 2016.

5. M. Omidi, M. Farhadi, and M. Jafari, "A comprehensive review on double pipe heat exchangers," Appl. Therm. Eng., vol. 110, pp. 1075-1090, 2017.

6. A. S. Dalkılıç, O. Acikgoz, M. A. Gümüş, and S. Wongwises, "Determination of Optimum Velocity for Various Nanofluids Flowing in a Double-Pipe Heat Exchanger," Heat Transf. Eng., vol. 38, no. 1, pp. 11-25, 2017.

7. A. Zarrella, G. Emmi, and M. De Carli, "A simulation-based analysis of variable flow pumping in ground source heat pump systems with different types of borehole heat exchangers: A case study," Energy Convers. Manag., vol. 131, pp. 135-150, 2016.

8. J. Luo, H. Zhao, S. Gui, W. Xiang, J. Rohn, and P. Blum, "Thermo-economic analysis of four different types of ground heat exchangers in energy piles," Appl. Therm. Eng., vol. 108, pp. 11-19, 2016.

9. H. S. Dizaji and S. Jafarmadar, "Experiments on New Arrangements of Convex and Concave Corrugated Tubes through a Double-pipe Heat Exchanger," Exp. Heat Transf., vol. 29, no. 5, pp. 577-592, 2015.

10. L. Qunhui, Z. Yangyan, and Y. Biao, "Numerical simulation study on the heat transfer characteristics of a double pipe heat exchanger," 2011 IEEE Power Eng. Autom. Conf., vol. 1, pp. 135-137, 2011. 